\title{
Off-Pump Multilayered Sutureless Repair for a Left Ventricular Blowout Rupture after Aortic Dissection Repair
}

\author{
Susumu Isoda ${ }^{*}$, Tamizo Kimura², Katsunori Tanaka², Kenji Nishimura², \\ Nozomu Yamanaka², Shin-ichi Taguchi², Keiji Uchida1, Norihisa Karube', \\ Kiyotaka Imoto ${ }^{1}$ \\ ${ }^{1}$ Department of Cardiovascular Surgery, Yokohama City University Medical Center, Yokohama, Japan \\ ${ }^{2}$ Department of Cardiovascular Surgery, National Defense Medical College, Tokorozawa, Japan \\ Email: ${ }^{\text {isoda@yokohama-cu.ac.jp }}$
}

Received 3 February 2015; accepted 22 February 2015; published 28 February 2015

Copyright (C) 2015 by authors and Scientific Research Publishing Inc.

This work is licensed under the Creative Commons Attribution International License (CC BY). http://creativecommons.org/licenses/by/4.0/

(c) (i) Open Access

\section{Abstract}

A left ventricular (LV) free wall rupture is a highly lethal condition. A 75-year-old female who experienced chest pain was diagnosed as having an acute aortic dissection Stanford type $A$ and underwent emergent surgery. Under cardiopulmonary bypass with LV venting through the right superior pulmonary vein, a proximal aortic stamp was formed. The patient was cooled, selective antegrade brain perfusion was performed, and a hemiarch repair was performed. After the patient was transferred to the intensive care unit, her blood pressure suddenly fell to $50 \mathrm{mmHg}$. She had a blowout rupture in the left ventricular anterolateral free wall. Since the bleeding hall was not large and the damage to the surrounding left ventricular tissue was not very wide, an off-pump multilayered sutureless repair was performed by using three layers of collagen fleece squares with fibrinogen-based impregnation (TachoComb; CSL Behring, Tokyo, Japan) and three layers of gelatin-resorcin-formalin glue reinforced by an equine pericardial patch (Xenomedica; Edwards Lifesciences, LLC, Irvine, CA). The blow-out rupture seemed to be caused by perioperative myocardial infarction generated by the compression of the left ventricular vent to the LV lateral wall. The patient was free from re-rupture or aneurysm enlargement. The thickness of the hemostatic material seemed to help control the bulging of the aneurysm and to prevent further LV aneurysm enlargement and re-rupture.

\section{Keywords}

Blowout, Cardiac Rupture, Sutureless Repair, Aortic Dissection, TachoComb

\footnotetext{
${ }^{*}$ Corresponding author.
}

How to cite this paper: Isoda, S., Kimura, T., Tanaka, K., Nishimura, K., Yamanaka, N., Taguchi, S., Uchida, K., Karube, N. and Imoto, K. (2015) Off-Pump Multilayered Sutureless Repair for a Left Ventricular Blowout Rupture after Aortic Dissection Repair. Open Journal of Thoracic Surgery, 5, 10-14. http://dx.doi.org/10.4236/ojts.2015.51003 


\section{Introduction}

A left ventricular (LV) free wall rupture represents an emergency, especially if it is a blowout rupture [1]-[3]. The sutureless patch has been recently used to repair LV free wall ruptures [4] [5]. However, using sutureless patches to repair a blowout rupture is controversial because of the later development of re-rupture or formation of a pseudoaneurysm [6] [7]. In this paper, we report a case of LV blowout rupture that was caused by myocardial infarction at the anterolateral wall of the left ventricle that was generated by compression of the left ventricular vent. It was treated by an off-pump sutureless repair that used multiple layers of collagen fleece with fibrinogen-based impregnation (TachoComb; CSL Behring, Tokyo, Japan) and gelatin-resorcin-formalin (GRF) glue (Nippon BXI Inc., Tokyo, Japan) reinforced by an equine pericardial patch (Xenomedica; Edwards Lifesciences, LLC, Irvine, CA, USA).

\section{Case Report}

A 75-year-old female who experienced sudden chest pain was admitted to an affiliated hospital and was diagnosed as having an acute aortic dissection Stanford type A. Hypertension tension and diabetes mellitus had been medically controlled. Computed tomography showed ascending aorta enlargement to $5.0 \mathrm{~cm}$ and pericardial effusion storage. Her blood pressure was $90 / 70 \mathrm{mmHg}$, and her electrocardiogram showed Q wave at lead III when she was transferred to our hospital. Emergent surgery was performed. Pericardiotomy revealed massive bloody effusion. Her vital signs improved. Under cardiopulmonary bypass and cardiac arrest with left ventricular venting through the right superior pulmonary vein, a proximal aortic stamp was formed and the aortic valve was suspended at the commissures. The patient was cooled to $22^{\circ} \mathrm{C}$, her circulation was temporarily stopped, and selective antegrade brain perfusion and inferior half body was perfused using a descending aortic occlusion balloon. An entry was not detected in the ascending, arch and the proximal descending aorta. A hemiarch repair was performed.

The cardiac arrest time was 240 minutes and the cardiopulmonary bypass time was 335 minutes. Myocardial protection during cardiac arrest was performed using antegrade and retrograde cold blood cardioplegia, which was followed by a terminal hot shot via antegrade and retrograde and controlled aortic root reperfusion. The heart beat spontaneously recovered. The patient was weaned from cardiopulmonary bypass uneventfully.

After the patient was transferred to the intensive care unit, her systolic blood pressure gradually increased to more than $140 \mathrm{mmHg}$, and then suddenly fell to $50 \mathrm{mmHg}$. The electrocardiogram showed ST changes in leads II, III, and aVF, and new Q wave was not seen. Pericardial drainage was increased, and massive bleeding was suspected. Her median sternotomy was reopened in the intensive care unit. There was pulsatile arterial blood blowing out from the left ventricular lateral free wall. The bleeding could be controlled by finger compression.

Intra-aortic balloon pumping was initiated to reduce the systolic tension of the left ventricular free wall. The patient was transferred to the operating room. There was a small laceration (which made a blood column with an approximately 2-mm width) and a surrounding limited damaged myocardium at the anterolateral wall of the left ventricle. Because the bleeding hall was not large and damage to the surrounding left ventricular tissue was small, an off-pump multilayered sutureless repair using three layers of collagen fleece squares with fibrinogenbased impregnation (i.e., TachoComb) and three layers of GRF glue (Nippon BXI Inc.) was alternately performed (Figure 1). To prevent an excessive amount of hardener and residual aldehyde from causing myocardial degeneration, the volume ratio of the glue and the hardener was strictly controlled to 10 to 1 , based on our previous study [8]. An equine pericardial patch (Xenomedica; Edwards Lifesciences. LLC) was attached to the surface using fibrin glue sealant (Bolheal; Chemo-Sero Therapeutic Research Institute, Kumamoto, Japan). The postoperative creatin kinase level was $890 \mathrm{IU} / \mathrm{dL}$ and the creatin kinase MB level was $51 \mathrm{IU} / \mathrm{dL}$, where creatin kinase level more than $50 \mathrm{IU} / \mathrm{dL}$ was estimated as perioperative myocardial infarction. The duration of the reoperation was 183 minutes. Postoperative neurological dysfunction was not noted. The pericardial drainage tube was removed on day 3. Intra-aortic balloon pumping was not used to maintain proper hemodynamics, but was used prophylactically to reduce the risk of aneurysm enlargement or re-rupture. It was terminated on postoperative day 5. The endotracheal tube was extubated on day 21.

Postoperative echocardiography revealed fibrin-like material at the external space of the anterior wall of the left and right ventricles. Six years after the surgery, the patient remains in good condition. A follow-up computed tomography image (Figure 2) revealed that the hemostatic material, which has a thickness of $12 \mathrm{~mm}$, still covered the surface of the left and right ventricle. There were no signs of re-rupture or aneurysm formation. 


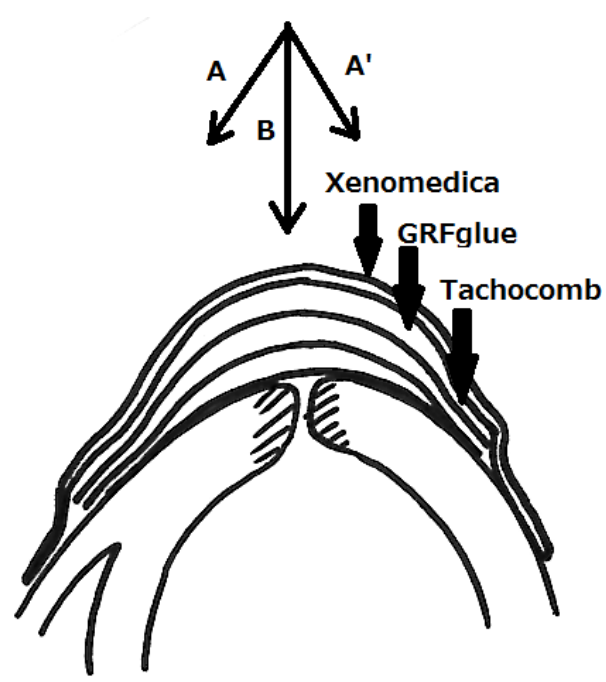

Figure 1. Schematic drawing of the sutureless repair method using multiple layers of TachoComb squares (CSL Behring, Tokyo, Japan) and GRF glue covered by a Xenomedica patch (Edwards Lifesciences, LLC, Irvine, CA, USA). Triple layers composed of TachoComb squares (CSL Behring), GRF glue and Xenomedica patch (Edwards Lifesciences. LLC) are attached to the epicardium. The bond of the adhesive onto the epicardium produces two opposing tension forces (indicated by oblique arrows A and A') on the three-layered patch. The addition (i.e., summation) of these two opposing forces creates a perpendicular force (indicated by vertical arrow B) against the left ventricular wall, which exerts the force needed to prevent enlargement of the aneurysm.

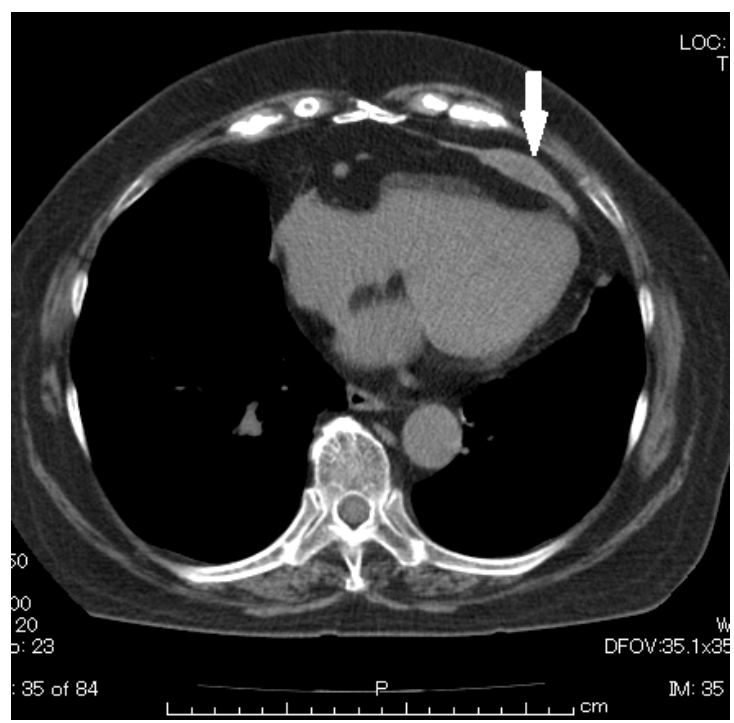

Figure 2. A preoperative computed tomography scan obtained 6 years after the surgery shows the hemostat material covers the ventricular free wall (indicated by the arrow). The thickness of the hemostat material is approximately $12 \mathrm{~mm}$.

\section{Discussion}

Left ventricular free wall rupture is a lethal condition with an incidence ranging from $0.8 \%$ to $6 \%$ in people who have had an acute myocardial infarction [9] [10]. A blowout rupture of the LV free wall represents an emergency of the first order [1]-[3]. We could treat our patient rapidly because she was in the intensive care unit when the rupture occurred.

The traditional repair of a LV free wall rupture involves direct suturing with or without cardiopulmonary bypass and infarctectomy with a patch under cardiopulmonary bypass [2] [11]. The use of a sutureless technique or a patch-and-glue technique has recently become popular [4] [5]. However, some reports suggest that the patchand-glue technique is unsuitable for patients with a blowout rupture [6] [7]. Nishizaki et al. [12] report the 
successful repair of a blowout rupture with an off-pump sutureless patch by using the TachoComb patch (CSL Behring) and equinus pericardium with fibrin spray. Amano et al. [13] used a double layer of bovine pericardium and GRF glue to treat a LV blowout rupture.

In our patient, the blowout rupture seemed to occur by a small perioperative myocardial infarction because of compression by the LV vent, which subsequently causes poor myocardial protection of the local area. The cardiac arrest time was not short (240 minutes), although the overall myocardial protection was acceptable because the postoperative peak creatine kinase MB level (51 IU/dL) revealed a borderline value of perioperative myocardial infarction (which is more than $50 \mathrm{IU}$ ). Therefore, we could treat the small blowout rupture with an offpump multilayered sutureless repair. Simple trauma by LV vent, degeneration of left ventricular wall, and potential coronary atherosclerosis might be the cause of the rupture.

We believe the thickness of the hemostatic material is essential for generating the force needed to push a LV aneurysm or damaged myocardium from the outside (Figure 1). The addition (i.e., summation) of the two opposing vectors of the tension forces created by the bond of the patch to the epicardium generates a third (i.e., vertical) vector that pushes against the LV aneurysm. The thickness of the hemostatic material is approximately directly proportional to the generated vertical force. Therefore, the thickness produced by the multilayered TachoComb patch (CSL Behring) and GRF glue patch is important for preventing the further formation of an aneurysm. Postoperative computed tomography images revealed that the thickness of the hemostatic material was approximately $12 \mathrm{~mm}$ (Figure 2).

\section{Conclusion}

A LV blowout rupture was caused by a small perioperative myocardial infarction because of compression of the $\mathrm{LV}$ vent and local poor myocardial protection during acute aortic dissection surgery. It was successfully treated with an off-pump multilayered sutureless repair by using a TachoComb patch (CSL Behring) and GRF glue patch reinforced by a Xenomedica patch (Edwards Lifesciences, LLC). The thickness of the hemostatic material seemed to prevent enlargement and re-rupture of the LV aneurysm. This technique can be available for repairing a blowout rupture that has a limited tear and a small necrotic area.

\section{Conflicts of Interest}

Susumu Isoda and the other authors have no conflicts of interest to declare.

\section{References}

[1] Purcaro, A., Costantini, C., Ciampani, N., Mazzanti, M., Silenzi, C., Gili, A., et al. (1997) Diagnostic Criteria and Management of Subacute Ventricular Free Wall Rupture Complicating Acute Myocardial Infarction. The American Journal of Cardiology, 80, 397-405. http://dx.doi.org/10.1016/S0002-9149(97)00385-8

[2] McMullan, M.H., Maples, M.D., Kilgore Jr., T.L. and Hindman, S.H. (2001) Surgical Experience with Left Ventricular Free Wall Rupture. The Annals of Thoracic Surgery, 71, 1894-1899. http://dx.doi.org/10.1016/S0003-4975(01)02625-X

[3] Tobara, T. (2004) Salvaged Cases of Blow-Out Type Cardiac Rupture Complicating Acute Myocardial Infarction. The Japanese Journal of Intensive Care Medicine, 28, 719-722. (In Japanese)

[4] Padro, J.M., Mesa, J.M., Silvestre, J., Larrea, J.L., Caralps, J.M., Cerron, F. and Aris, A. (1993) Subacute Cardiac Rupture: Repair with a Sutureless Technique. The Annals of Thoracic Surgery, 55, 20-24. http://dx.doi.org/10.1016/0003-4975(93)90468-W

[5] Lachapelle, K., deVarennes, B., Ergina, P.L. and Cecere, R. (2002) Sutureless Patch Technique for Postinfarction Left Ventricular Rupture. The Annals of Thoracic Surgery, 74, 96-101. http://dx.doi.org/10.1016/S0003-4975(02)03581-6

[6] Canovas, S.J., Lim, E., Dalmau, M.J., Bueno, M., Buendia, J., Hornerero, F., et al. (2003) Midterm Clinical and Echocardiographic Results with Patch Glue Repair of Left Ventricular Free Wall Rupture. Circulation, 108, II-237-II-240. http://dx.doi.org/10.1161/01.cir.0000089042.80722.7a

[7] Iha, K., Ikemura, R., Higa, N., Akasaki, M., Kuniyoshi, Y. and Koja, K. (2001) Left Ventricular Pseudoaneurysm after Sutureless Repair of Subacute Left Ventricular Free Wall Rupture: A Case Report. Annals of Thoracic and Cardiovascular Surgery, 7, 311-314.

[8] Isoda, S., Kimura, T., Mashiko, Y., Nakamura, S. and Maehara, T. (2011) In Vitro Study of the Optimum Volume Ratio of Activator to Adhesive in Gelatin-Resorcin-Formalin Glue. General Thoracic and Cardiovascular Surgery, 59, 
326-328. http://dx.doi.org/10.1007/s11748-009-0552-8

[9] Moreno, R., Lopez, E., Lopez-Sendon, J.L., Garcia, E., Sariano, J., Abeytua, M., et al. (2000) Frequency of Left Ventricular Free-Wall Rupture in Patient with Acute Myocardial Infarction Treated with Primary Angioplasty. The American Journal of Cardiology, 85, 757-760. http://dx.doi.org/10.1016/S0002-9149(99)00855-3

[10] Figueras, J., Alcalde, O., Barrabés, J.A., Serra, V., Alguersuari, J., Cortadellas, J. and Lidon, R.M. (2008) Changes in Hospital Mortality Rates in 425 Patients with Acute ST-Elevation Myocardial Infarction and Cardiac Rupture over a 30-Year Period. Circulation, 118, 2783-2789. http://dx.doi.org/10.1161/CIRCULATIONAHA.108.776690

[11] Kirklin, J.W. (2003) Left Ventricular Aneurysm. In: Kirklin, J.W. and Barrat-Boyes, B.G., Eds., Cardiac Surgery, 3rd Edition, Churchill Livingstone, London, 437-455.

[12] Nishizaki, K., Seki, T., Fujii, A., Nishida, Y. and Funabiki, M. (2004) Sutureless Patch Repair for Small Blowout Rupture of the Left Ventricle after Myocardial Infarction. The Japanese Journal of Thoracic and Cardiovascular Surgery, 52, 268-271. http://dx.doi.org/10.1007/s11748-004-0123-y

[13] Amano, H., Ohara, K., Nie, M., Torii, S., Miyoshi, Y. and Yoshimura, H. (2002) New Surgical Technique of Left Ventricular Free Wall Rupture: Double Patch Sealing Method. Annals of Thoracic and Cardiovascular Surgery, 8, 389392. 
Scientific Research Publishing (SCIRP) is one of the largest Open Access journal publishers. It is currently publishing more than 200 open access, online, peer-reviewed journals covering a wide range of academic disciplines. SCIRP serves the worldwide academic communities and contributes to the progress and application of science with its publication.

Other selected journals from SCIRP are listed as below. Submit your manuscript to us via either submit@scirp.org or Online Submission Portal.
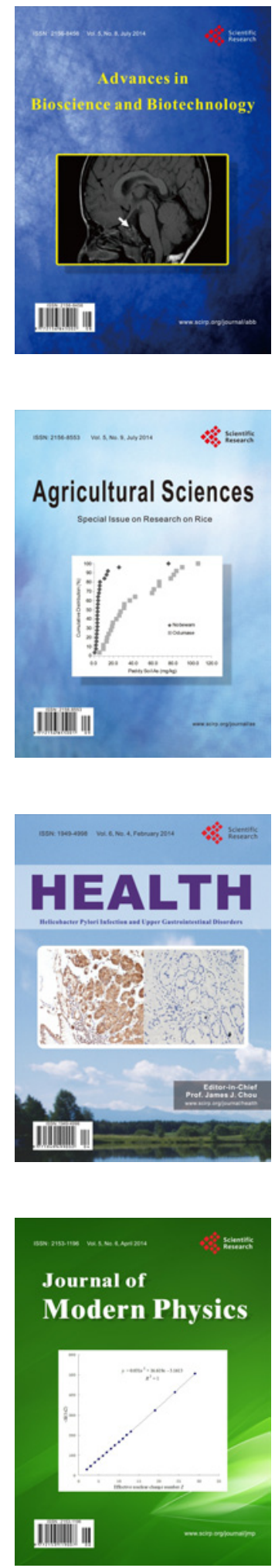
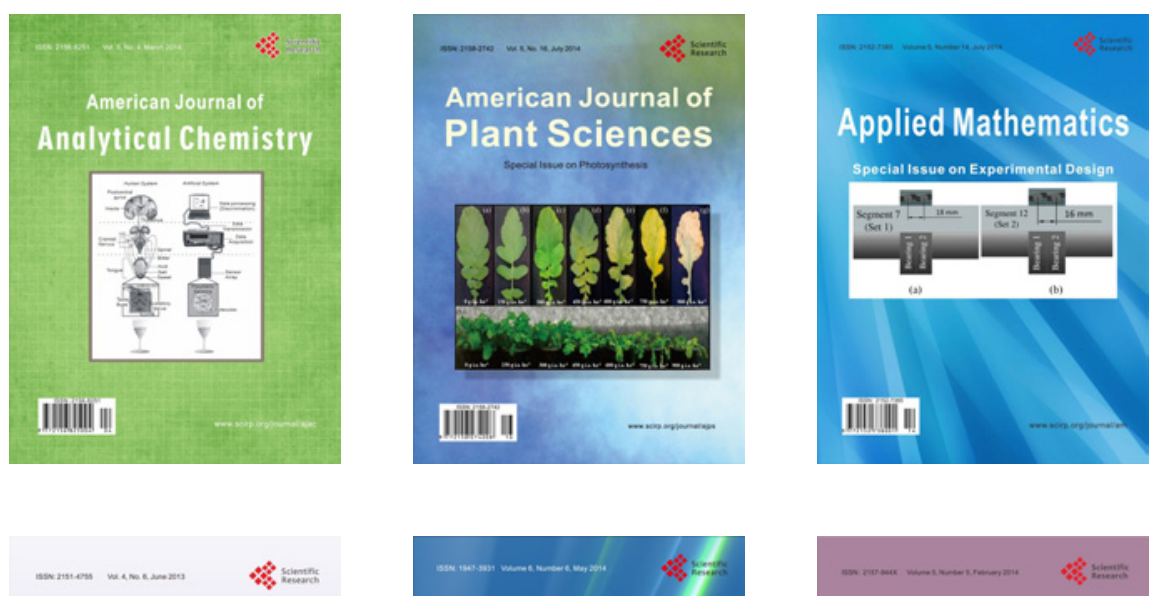

Creative Education
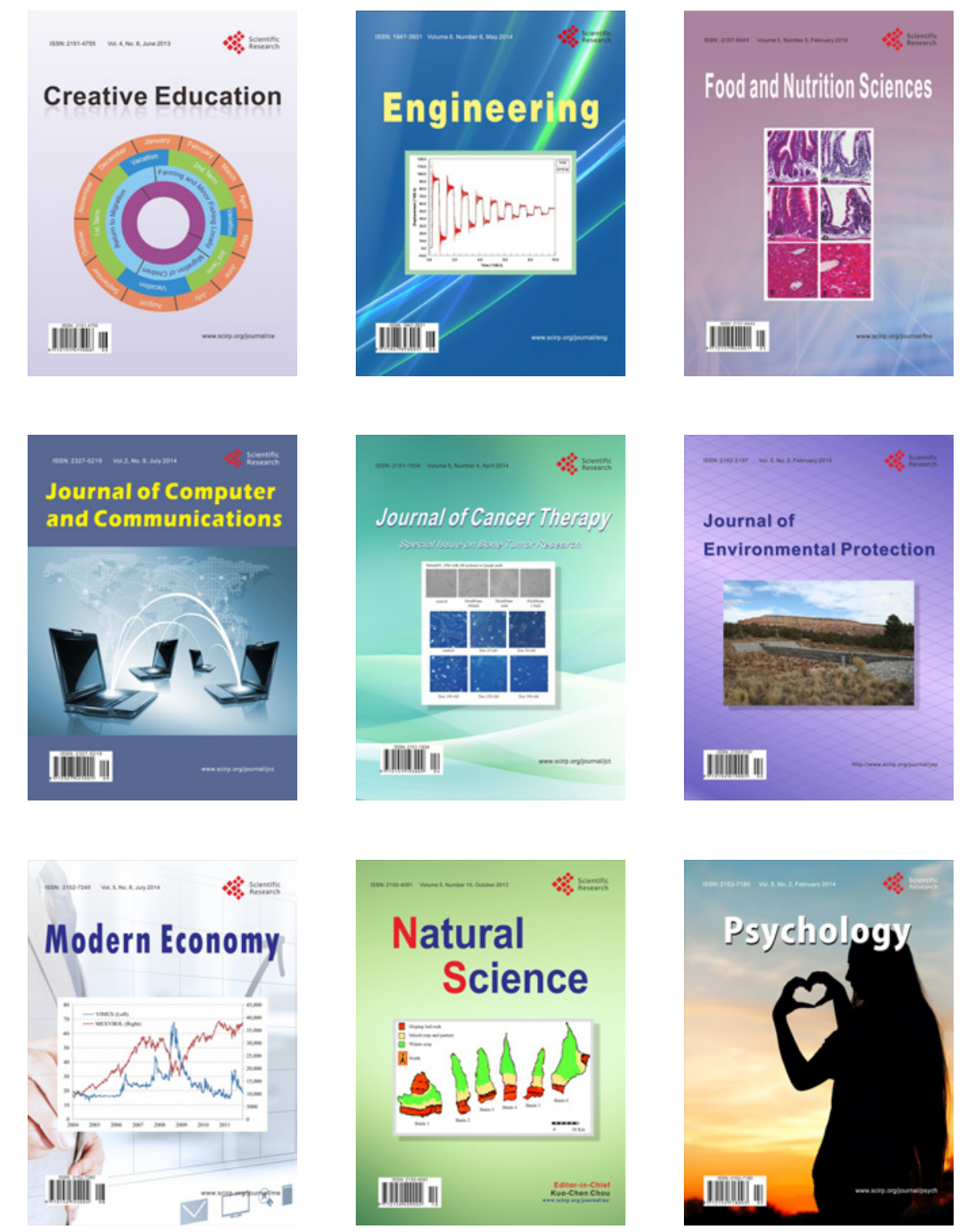